\title{
Comparative study on the characteristics and oxidation stability of commercial milk powder during storage
}

\author{
Y. H. Li, ${ }^{1 *}$ W. J. Wang, ${ }^{2}$ L. Guo, ${ }^{1}$ Z. P. Shao, ${ }^{1}$ and X. J. Xu ${ }^{1}$ \\ ${ }^{1}$ College of Food Science and Biotechnology Engineering, Zhejiang Gongshang University, Hangzhou 310018, China \\ ${ }^{2}$ Research and Development Institute, Zhejiang Yi Ming Food Co. Ltd., Wenzhou 325000, China
}

\begin{abstract}
The quality of milk powder can decrease during storage. In this study, the characteristics of 12 kinds of commercial milk powder from China were investigated. Changes in various indicators were tracked to comprehensively estimate the oxidation stability of different commercial milk powders. The components of the commercial milk powder were different. The percentages of milk fat, protein, and carbohydrates ranged from 9.8 to $28.5 \mathrm{~g} / 100 \mathrm{~g}, 15.0$ to $24.0 \mathrm{~g} / 100 \mathrm{~g}$, and 32.0 to 67.5 $\mathrm{g} / 100 \mathrm{~g}$, respectively. The water activities ranged from 0.2394 to 0.5286 . The diameters of the milk fat globules in different commercial milk powder ranged from 13.99 to $41.09 \mathrm{~nm}$. At the same time, the peroxide value of the control sample was low $(\leq 0.14 \mathrm{mEq} / \mathrm{kg})$. After 3 mo of storage, the peroxide values of some of the commercial milk powder increased significantly. The changes in the thiobarbituric acid values during storage did not follow a common trend. The contents of free fat in the different control samples were 0.21 to $1.67 \mathrm{~g} / 100$ $\mathrm{g}$, and these values did not increase during storage. After 3 mo of storage, the hydroxymethyl furfural values and $\mathrm{b}$ color values of the different commercial milk powder reached their highest levels. The concentrations of typical oxidized flavor compounds in different commercial milk powder increased greatly with prolonged storage time. The level of hexanal was the highest, and the contents in all the samples ranged from 28.56 to $4,071.28 \mu \mathrm{g} / \mathrm{kg}$ after $6 \mathrm{mo}$ of storage and from 5.91 to $6,281.37 \mu \mathrm{g} / \mathrm{kg}$ after $12 \mathrm{mo}$ of storage. Free radicals were found in some of the stored milk powder, and these were shown as single peaks or multiple peaks. The ratios of the peak areas and masses reached $12.42 \times 10^{6}$ to $14.26 \times 10^{8}$. However, the presence of free radicals in the commercial milk powder was not consistent. The water activities and diameters of the fat globules in the
\end{abstract}

Received December 3, 2018.

Accepted June 8, 2019.

*Corresponding author: liyanhua607@163.com commercial milk powder were highly correlated with their oxidation stabilities during storage.

Key words: oxidation stability, commercial milk powder, storage

\section{INTRODUCTION}

Milk powder maintains most of the nutrients of raw milk, and the moisture content is dramatically decreased for preservation. However, the decrease in the oxidation stability of milk powder during processing and storage is the main bottleneck limiting its edibility and applicability (Hough et al., 2002; Cluskey et al., 2006; Li et al., 2013a).

The oxidation stability of milk powder can be affected by many factors, such as the properties of raw milk, processing, and storage conditions. With prolongation of storage time, milk fat oxidation, Maillard reaction, and lactose crystallization can continue, and all of these reactions reduce the quality of milk powder. Milk fat oxidation is a very complex process. The fatty acids are released and volatile carbonyls, lactones, acids, hydrocarbons, esters, alcohols, and other compounds are formed by oxidation, dehydration, decarboxylation, reduction, and hydrolysis (Nursten, 1997). These volatiles play an important role in the flavor of milk powder. Aldehydes and ketones are closely related to the oxidation of milk powder (Li et al., 2013a). A high peroxide value can be produced by lipid oxidation in infant formulas (Romeu-Nadal et al., 2007; Cesa et al., 2012). In addition, the Maillard reaction between lactose and proteins can occur during the storage of milk powder, and this reaction can also change the color, flavor, and nutritional properties of milk powder.

The compositions of formula milk powder are complex, especially those of infant formula milk powder. Supplementation of special long-chain PUFA is a new direction in infant formula milk powder. During processing, various PUFA or purified concentrated oils are added, and a large number of vitamins, trace elements, and other substances are also added to infant formula milk powder. Therefore, the oxidation stability 
is a critical problem. The oxidation stability of milk powder could be controlled by improving the processing methods and storage conditions (Turner et al., 2002; Birchal et al., 2005; Whetstine and Drake, 2007). The particle characteristics, such as particle sizes, water activities, and microstructures, are different in milk powder produced by different processes (Birchal et al., 2005; Vignolles et al., 2007; Li et al., 2013a).

Stapelfeldt et al. (1997) noted that the level of free radicals in low-heated milk powder was high after storage at $45^{\circ} \mathrm{C}$ for $47 \mathrm{~d}$, and no significant differences were observed in the sensory scores among milk powder with different water activities. That study also indicated the high-heated milk powder had peroxide values that were higher than those of low-heat milk powder. Cluskey et al. (2006) indicated that the peroxide values of low-heat milk powder were higher than those of high-heated milk powder with prolonged storage time. Based on those studies, the content of free radicals and peroxide values could change during the processing and storage of milk powder.

This study analyzed the differences in the components of commercial milk powder and tracked indicators related to oxidation reactions and Maillard reaction to evaluate the oxidation stability of commercial milk powder from China and provide a theoretical basis for improving formula milk powder.

\section{MATERIALS AND METHODS}

\section{Analysis of the Components in Commercial Milk Powder}

Nine kinds of infant formula milk powder (named YPP4, AP3, AP4, BP3, DP3, JP3, SP4, SP5, and SP6) and 3 kinds of whole milk powder (named S1, $\mathrm{S} 2$, and S3) were ordered from a market in China. The milk powder samples were taken immediately after manufacture and were considered the control samples. These milk powder should be stored hermetically at room temperature. The contents of milk fat, protein, and carbohydrates in the different samples were determined by the Rose-Gottlieb method, the Kjeldahl method, and HPLC, respectively (Guinee et al., 2000; Lynch et al., 2002; Li et al., 2012). The water activity was determined using a water activity meter (Aqualab 4Tev, Decagon, Keshenghang Inc., Hangzhou, China). The particle size of the milk powder was determined by optical microscopy. After the milk powder was reconstituted $(12 \%, \mathrm{wt} / \mathrm{vol})$, the mean diameters of the milk fat globules in the samples were determined using a particle size analyzer (ZetaPLAS, Brookhaven Instruments Corporation, Holtsville, NY) at $40^{\circ} \mathrm{C}$ in a water bath
(Ye et al., 2004). The globule size is expressed as $d_{32}$, and the average fat globule diameter was calculated.

\section{Determination of the Peroxide Value}

The peroxide value (POV) was determined according to the method described previously (Zou, 2009). Milk powder sample $(5.0 \mathrm{~g})$ was mixed with chloroformglacial acetic acid solution (40:60, vol/vol, $5 \mathrm{~mL}$ ), and saturated potassium iodide solution $(1 \mathrm{~mL})$ was added. The mixture was reacted in the dark for $3 \mathrm{~min}$. Then, it was diluted with distilled water $(50 \mathrm{~mL})$ and added to starch solution $(1 \%, \mathrm{wt} / \mathrm{vol}, 1 \mathrm{~mL})$. The clear liquor was separated by filtration, and the POV was determined at $585 \mathrm{~nm}$.

\section{Determination of the Thiobarbituric Acid Value}

The thiobarbituric acid (TBA) value was determined according to the method described previously (Sun, 2013). The milk powder was reconstituted $(12 \%$, wt/ vol) and the reconstituted milk $(35.2 \mathrm{~mL})$ was kept in a water bath $\left(30^{\circ} \mathrm{C}\right)$. Then, trichloroacetic acid solution (40\%, wt/vol, $2 \mathrm{~mL}$ ) and ethanol solution $(95 \%, 4 \mathrm{~mL})$ were added. After shaking, the mixture was allowed to rest for $15 \mathrm{~min}$. Then, the milk fat and proteins were removed by filtration. The TBA solution $(0.1 \mathrm{~mol} / \mathrm{L}$, $1.0 \mathrm{~mL}$ ) was added to the clarified filtrate, and the mixture was incubated in a water bath $\left(60^{\circ} \mathrm{C}\right)$ for 60 min. The absorbance was measured at $538 \mathrm{~nm}$ at room temperature.

\section{Free Fat on the Surface of Commercial Milk Powder}

Milk powder sample $(5.0 \mathrm{~g})$ was added to petroleum ether $\left(50 \mathrm{~mL}\right.$, the boiling point was $\left.30-60^{\circ} \mathrm{C}\right)$ and left to stand for $12 \mathrm{~h}$. The sample was sealed immediately, and the free fat dissolved at room temperature over $15 \mathrm{~min}$. The content of free fat was determined after evaporation.

\section{Determination of Hydroxymethyl Furfural}

The value of hydroxymethyl furfural (HMF) was determined according to the method described previously (Keeney and Bassette, 1959; Chavez-Servin et al., 2006). Milk powder sample (5.0 g) was added to oxalic acid solution $(0.3 \mathrm{~mol} / \mathrm{L}, 5 \mathrm{~mL})$. Trichloroacetic acid solution ( $40 \%$, wt/vol, $5 \mathrm{~mL}$ ) was added, and the mixture was allowed to stand for 15 min after shaking. Then, the mixture was centrifuged at $4,000 \times g$ for 15 min at room temperature. The TBA $(0.05 \mathrm{~mol} / \mathrm{L}, 1$ $\mathrm{mL}$ ) was added to the supernatant, and this mixture 
was kept in a water bath $\left(40^{\circ} \mathrm{C}\right)$ for $30 \mathrm{~min}$. The detection of HMF was performed at $443 \mathrm{~nm}$.

\section{Determination of the Color Value}

The color change mainly provides the information about Maillard reaction in milk powder. In this study, the differences in the color values among the commercial milk powder were measured using a colorimeter (Chroma Meter CR-400, Keshenghang Inc.). The color parameters $\mathrm{L}$ and $\mathrm{b}$ values were analyzed to compare the color changes in different milk powder. The $\mathrm{L}$ value represents brightness, $\mathrm{L}=0$ is defined as black and $\mathrm{L}$ $=100$ as white. The $\mathrm{b}$ value represents yellowness to blueness, and positive values represent yellowness.

\section{Determination of Oxidation Flavor Compounds in Commercial Milk Powder}

The volatiles in the reconstituted commercial milk powder were extracted and analyzed using solid-phase microextraction GC-MS according to a previous study (Li et al., 2013b). Hexanal, heptanal, nonanal, 2-heptanone, and 2-nonanone, as the selected oxidized volatiles, were identified by comparison to the NIST-02L GC-MS spectrum library and the retention time of their standard chemicals (Sigma, St. Louis, MO).

\section{Free Radicals in the Commercial Milk Powder During Storage}

The radical was measured by an electron spin resonance spectrometer (Bruker BioSpin GmbH, Hamburg, Germany). Electron spin resonance analysis was conducted based on the method described by Thomsen et al. $(2005 \mathrm{a}, \mathrm{b})$. The following instrument parameters were used: sweep width, 100 Gauss; microwave power,
$3.10 \mathrm{~mW}$; modulation amplitude, 1.00 Gauss; receiver gain, $5.02 \times 10^{4}$; time constant, $40.96 \mathrm{~ms}$; conversion time, $160 \mathrm{~ms}$; and total sweep time, $163.84 \mathrm{~s}$.

\section{Statistical Analysis}

Experimental data were statistically analyzed using PASW Statistics 18.0 Software (SPSS Inc., Chicago, IL). One-way and univariate ANOVA were applied to examine the effects of different treatments. Data are expressed as the mean \pm standard deviation. Duncan's multiple range test was performed for post hoc multiple comparisons with the level of significance set at $P<$ 0.05. Pearson correlation coefficients were calculated using the bivariate analysis.

\section{RESULTS AND DISCUSSION}

\section{Analysis of Milk Composition in the Commercial Milk Powder}

Table 1 shows the changes in the main components of 12 kinds of commercial milk powder. Obvious differences were observed in the components of the different milk powder samples. The contents of milk fat, proteins, and carbohydrates ranged from 9.8 to 28.5 $\mathrm{g} / 100 \mathrm{~g}, 15.0$ to $24.0 \mathrm{~g} / 100 \mathrm{~g}$, and 37.0 to $62.5 \mathrm{~g} / 100$ $\mathrm{g}$, respectively. Those differences could inevitably affect the characteristics of the milk powder during storage because milk fat can readily undergo lipid oxidation during storage (Lloyd et al., 2009), whereas the proteins and carbohydrates can undergo Maillard reaction (Thomsen et al., 2005a). The range of water activities in the different commercial milk powder was 0.2394 to 0.5286. The levels in YPP4 and AP3 were 0.5286 and 0.3903 , respectively, which were higher than those of the other samples $(P<0.05)$. Water activity can affect stability during storage. A low water activity can

Table 1. Changes in the characteristics of the commercial milk powder (mean $\pm \mathrm{SD}$ )

\begin{tabular}{|c|c|c|c|c|c|c|}
\hline Sample & $\begin{array}{l}\text { Milk fat } \\
(\mathrm{g} / 100 \mathrm{~g})\end{array}$ & $\begin{array}{l}\text { Protein } \\
(\mathrm{g} / 100 \mathrm{~g})\end{array}$ & $\begin{array}{l}\text { Carbohydrate } \\
(\mathrm{g} / 100 \mathrm{~g})\end{array}$ & $\begin{array}{l}\text { Water } \\
\text { activity }\end{array}$ & $\begin{array}{l}\text { Particle size } \\
\quad(\mathrm{mm})\end{array}$ & $\begin{array}{l}\text { Diameter of } \\
\text { fat globules }(\mathrm{nm})\end{array}$ \\
\hline YPP4 & $15.9 \pm 0.3^{\mathrm{e}}$ & $17.5 \pm 0.5^{\text {cde }}$ & $57.4 \pm 2.1^{\mathrm{ab}}$ & $0.5286^{\mathrm{a}}$ & $0.97 \pm 0.36^{\mathrm{b}}$ & $41.1 \pm 0.5^{\mathrm{a}}$ \\
\hline AP3 & $16.6 \pm 0.2^{\mathrm{de}}$ & $17.1 \pm 0.4^{\text {cde }}$ & $58.0 \pm 2.5^{\mathrm{ab}}$ & $0.3903^{\mathrm{b}}$ & $0.89 \pm 0.14^{\mathrm{b}}$ & $28.2 \pm 1.0^{\mathrm{c}}$ \\
\hline $\mathrm{AP} 4$ & $11.6 \pm 0.3^{\mathrm{f}}$ & $20.0 \pm 0.6^{\mathrm{b}}$ & $58.0 \pm 3.1^{\mathrm{ab}}$ & $0.3126^{\text {de }}$ & $2.03 \pm 0.42^{\mathrm{a}}$ & $22.9 \pm 0.4^{\mathrm{d}}$ \\
\hline BP3 & $21.3 \pm 0.5^{\mathrm{b}}$ & $16.4 \pm 0.5^{\mathrm{def}}$ & $55.6 \pm 2.5^{\mathrm{ab}}$ & $0.3179^{\text {de }}$ & $0.62 \pm 0.19^{\mathrm{b}}$ & $18.4 \pm 0.5^{\mathrm{fg}}$ \\
\hline DP3 & $16.2 \pm 0.4^{\mathrm{e}}$ & $16.0 \pm 0.6^{\mathrm{ef}}$ & $46.1 \pm 2.7^{\mathrm{c}}$ & $0.3047^{\mathrm{e}}$ & $0.95 \pm 0.20^{\mathrm{b}}$ & $28.0 \pm 0.8^{c}$ \\
\hline JP3 & $20.5 \pm 0.4^{\mathrm{bc}}$ & $17.4 \pm 0.4^{\text {cde }}$ & $54.8 \pm 2.9^{\mathrm{b}}$ & $0.3146^{\text {de }}$ & $0.67 \pm 0.15^{\mathrm{b}}$ & $18.0 \pm 0.2^{\mathrm{g}}$ \\
\hline SP4 & $20.2 \pm 0.4^{\mathrm{bc}}$ & $15.0 \pm 0.4^{\mathrm{f}}$ & $59.1 \pm 2.8^{\mathrm{ab}}$ & $0.3516^{\mathrm{c}}$ & $0.42 \pm 0.03^{\mathrm{b}}$ & $38.5 \pm 1.2^{\mathrm{b}}$ \\
\hline SP5 & $19.4 \pm 0.5^{\mathrm{c}}$ & $18.1 \pm 0.6^{\mathrm{cd}}$ & $56.0 \pm 2.8^{\mathrm{ab}}$ & $0.2698^{\mathrm{f}}$ & $0.51 \pm 0.05^{\mathrm{b}}$ & $14.2 \pm 0.3^{\mathrm{h}}$ \\
\hline SP6 & $17.9 \pm 0.5^{\mathrm{d}}$ & $17.0 \pm 0.6^{\text {cde }}$ & $55.4 \pm 2.2^{\mathrm{ab}}$ & $0.2661^{\mathrm{f}}$ & $0.69 \pm 0.10^{\mathrm{b}}$ & $14.0 \pm 0.3^{\mathrm{h}}$ \\
\hline $\mathrm{S} 1$ & $28.5 \pm 0.8^{\mathrm{a}}$ & $24.0 \pm 0.7^{\mathrm{a}}$ & $37.0 \pm 1.8^{\mathrm{d}}$ & $0.3209^{\mathrm{d}}$ & $0.85 \pm 0.33^{\mathrm{b}}$ & $27.8 \pm 0.7^{\mathrm{c}}$ \\
\hline $\mathrm{S} 2$ & $9.8 \pm 0.4^{\mathrm{g}}$ & $18.6 \pm 0.6^{\mathrm{bc}}$ & $62.5 \pm 3.4^{\mathrm{a}}$ & $0.2469^{\mathrm{g}}$ & $0.90 \pm 0.19^{\mathrm{b}}$ & $20.0 \pm 0.5^{\mathrm{ef}}$ \\
\hline S3 & $28.5 \pm 0.6^{\mathrm{a}}$ & $23.8 \pm 0.6^{\mathrm{a}}$ & $41.6 \pm 2.1^{\mathrm{cd}}$ & $0.2394^{\mathrm{g}}$ & $0.80 \pm 0.18^{\mathrm{b}}$ & $21.0 \pm 0.5^{\mathrm{de}}$ \\
\hline
\end{tabular}

${ }^{\mathrm{a}-\mathrm{h}}$ Different lowercase letters in the same column indicate significant differences between the samples $(P<0.05)$. 
reduce the degree of oxidation and prolong the shelf life of milk powder (Stapelfeldt et al., 1997).

The AP4 sample had the largest particle size (2.03 $\mathrm{mm}$ ), and the particle sizes of the other samples ranged from 0.42 to $0.97 \mathrm{~mm}$. The diameters of the fat globules $\left(\mathrm{d}_{32}\right)$ ranged from 13.99 to $41.09 \mathrm{~nm}$. The fat globules in YPP4 were largest and were significantly larger than those in the other samples $(P<0.05)$. The SP5 and SP6 had smaller milk fat globules. The composition and particle characteristics of the milk powder were different after granulation and formulation processes, which can affect the solubility, dispersion, and oxidation stability during storage (Murrieta-Pazos et al., 2012).

\section{Oxidation Indicators in Commercial Milk Powder During Storage}

Changes in the POV. Peroxide is the primary oxidation product produced during the lipid oxidation. The POV can indicate the content of peroxide and is generally used as an indicator to evaluate the primary oxidation of milk powder. Figure 1 shows the
POV of the commercial milk powder during storage. The POV of the control sample was low. The POV of control S3 was the highest $(0.14 \mathrm{mEq} / \mathrm{kg})$. After 3 mo of storage, the POV had changed significantly (with the exceptions of AP4, DP3, SP4, and S3; $P<0.05$ ), which indicated that short-term storage could affect the POV of commercial milk powder. During further storage, the POV of different commercial milk powder increased significantly compared with those of corresponding control samples $(P<0.05)$. The POV of AP3 and AP4 changed slightly, whereas those of SP6 and BP3 increased substantially. In BP3, the POV reached $11.23 \mathrm{mEq} / \mathrm{kg}$ after storage for $6 \mathrm{mo}$ and reached to $8.74 \mathrm{mEq} / \mathrm{kg}$ after storage for $9 \mathrm{mo}$. The POV is closely related to lipid oxidation (Cluskey et al., 2006; Romeu-Nadal et al., 2007). The POV tends to increase during short-term storage and to decrease for further storage. The increase in the POV indicated an accumulation of intermediates formed from lipid oxidation in the sample, whereas a decrease in the POV can be attributed to further oxidation with the formation of small molecules, such as aldehydes, ketones, and acids (Nursten, 1997).

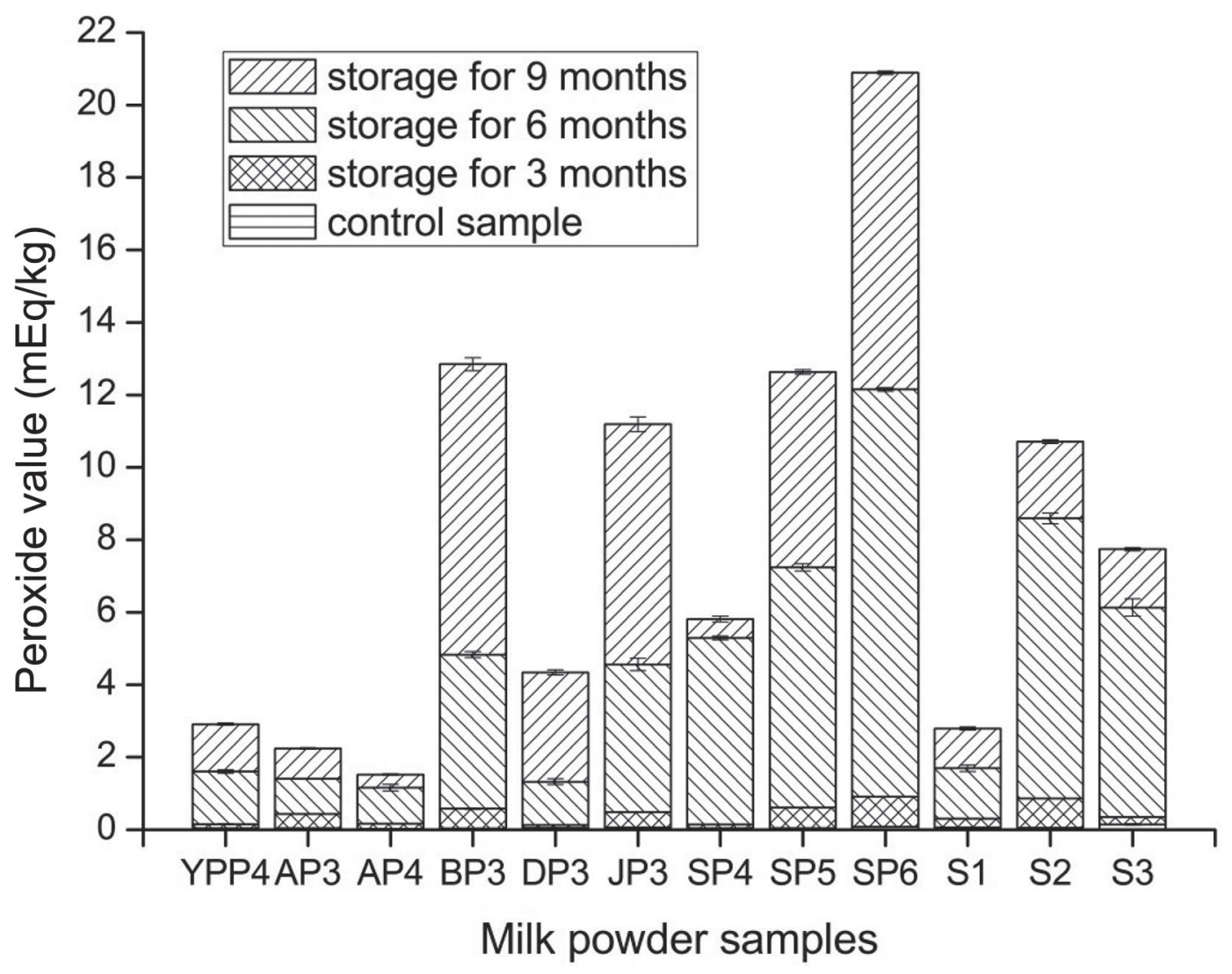

Figure 1. Changes in the peroxide values of the commercial milk powder during storage. Infant formula milk powder $=$ YPP4, AP3, AP4, BP3, DP3, JP3, SP4, SP5, and SP6; whole milk powder = S1, S2, and S3. Data are expressed as mean values \pm SD. 
Value of TBA in the Commercial Milk Powder. The TBA value indicates the magnitude of the TBA reactive substances, a group of substances that are products of lipid peroxidation and are generated by the further degradation of lipid hydroperoxides. The TBA reactive substances value is the main parameter to reflecting the further oxidation of milk fat in the system (Guillen-Sans and Guzman-Chozas, 1995). Figure 2 shows the TBA values during storage. It was found that the TBA values of infant formula milk powder were much larger than those of whole milk powder. The TBA values of SP6 were the highest (ranging from 0.477 to 0.880 ) and those of SP4 were the lowest (ranging from 0.054 to 0.104). Among the whole milk powder, the values of TBA ranged from 0.044 to 0.221 . In this study, the TBA values of different commercial milk powder changed irregularly, which indicated that lipid oxidation varied dramatically during storage.

Changes in the Contents of Free Fat. The free fat content, an important index for evaluating the quality of milk powder, is considered to be the main reason for changes in oxidation flavors, the decrease in rehydration, and the fluidity of milk powder in the drying industry (Marie-Laure et al., 2007). Free fat can originate from a physical damage due to shrinkage in the early stages of spray drying and the storage conditions (Marie-Laure et al., 2010). Figure 3 shows the contents of free fat in the commercial milk powder during storage. The contents of free fat in the control samples were 0.21 to $1.67 \mathrm{~g} / 100 \mathrm{~g}$. After storage, the content of free fat in YPP4 increased significantly $(P$ $<0.05)$, and it increased to $8.71 \mathrm{~g} / 100 \mathrm{~g}$ after $9 \mathrm{mo}$ of storage. In addition to YPP4, the contents of free fat in S1 (1.67-1.91 g/100 g) were higher than those of the other samples, and the value did not change significantly during storage $(P>0.05)$. The content of free fat in S2 was the lowest, and it was only 0.19 to $0.25 \mathrm{~g} / 100 \mathrm{~g}$ during storage $(P>0.05)$. Surface free fats existed on the outer surface and the inner pore surface of milk powder particles, and these fats are an important factor in oxidation during storage (Vignolles et al., 2007; Zafar et al., 2017). The contents of free fat in most commercial milk powder did not increase significantly during storage, indicating that the content of free fat could not fully reflect the oxidation stability during storage.

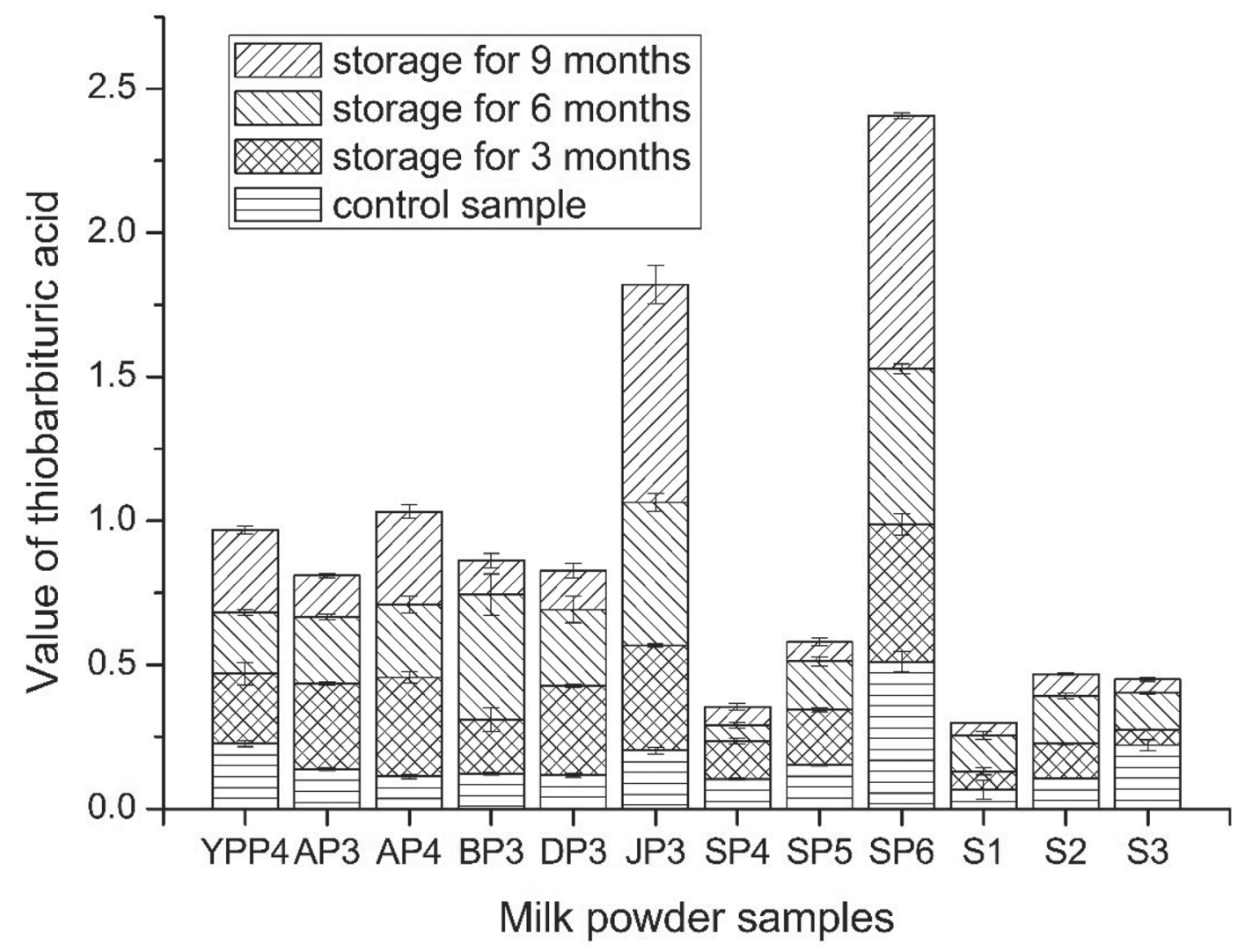

Figure 2. Values of thiobarbituric acid among the commercial milk powders. Infant formula milk powder = YPP4, AP3, AP4, BP3, DP3, JP3, SP4, SP5, and SP6; whole milk powder $=$ S1, S2, and S3. Data are expressed as mean values \pm SD. 


\section{Evaluation of Maillard Reaction in Commercial Milk Powder}

Changes in the HMF Value During Storage. Hydroxymethyl furfural is an intermediate product of Maillard reaction, and it can indicate the degree of Maillard reaction during the storage of milk powder. The HMF values of the control samples were 0.075 to 0.322 (Figure 4). The value of YPP4 was the highest followed by DP3 and AP4. The HMF values of S1 and S3 were the lowest. The reducing sugars in the milk powder could be dehydrated into HMF via the Maillard reaction (Chavez-Servin et al., 2015). The HMF values of the infant formula milk powder ranged from 0.119 to 0.836 during storage, and these values are higher than those of the whole milk powder $(0.070-0.296)$. The HMF values of AP3 were significantly higher than those of the other samples $(P<0.05)$. However, the values in SP4 changed only slightly and ranged from 0.119 to 0.202. Compared with other samples, the HMF values of the $\mathrm{S} 1$ samples were the lowest during storage (0.070-0.178). The HMF values of most of the commercial milk powder samples increased during short-term storage and then decreased. After 3 mo of storage, the HMF values of the different commercial milk powder reached their maxima (except S3), which also indicated that the HMF was an intermediate product generated during storage.

Changes in the Color Values of Commercial Milk Powder. The color change mainly provides information about Maillard reaction in milk powder, which could reduce the sensory quality of products. In this study, b and L color values can effectively indicate the color changes in the milk powder during storage. The $\mathrm{b}$ and $\mathrm{L}$ values of the different samples are shown in Tables 2 and 3, respectively. No differences were observed in the color values between the infant formula milk powder and whole milk powder. Positive values of $\mathrm{b}$ indicate the yellowness, and $\mathrm{L}$ is a measure of brightness. The $b$ values of the control samples were low and ranged from 14.87 to 18.15 . With the prolongation of storage time, the $\mathrm{b}$ values increased during short-term storage and then decreased. The value of $b$ was highest after 3 mo of storage (except for YPP4).

The control samples had the highest $\mathrm{L}$ values, and they ranged from 98.28 to 100.28 . The $\mathrm{L}$ values tended

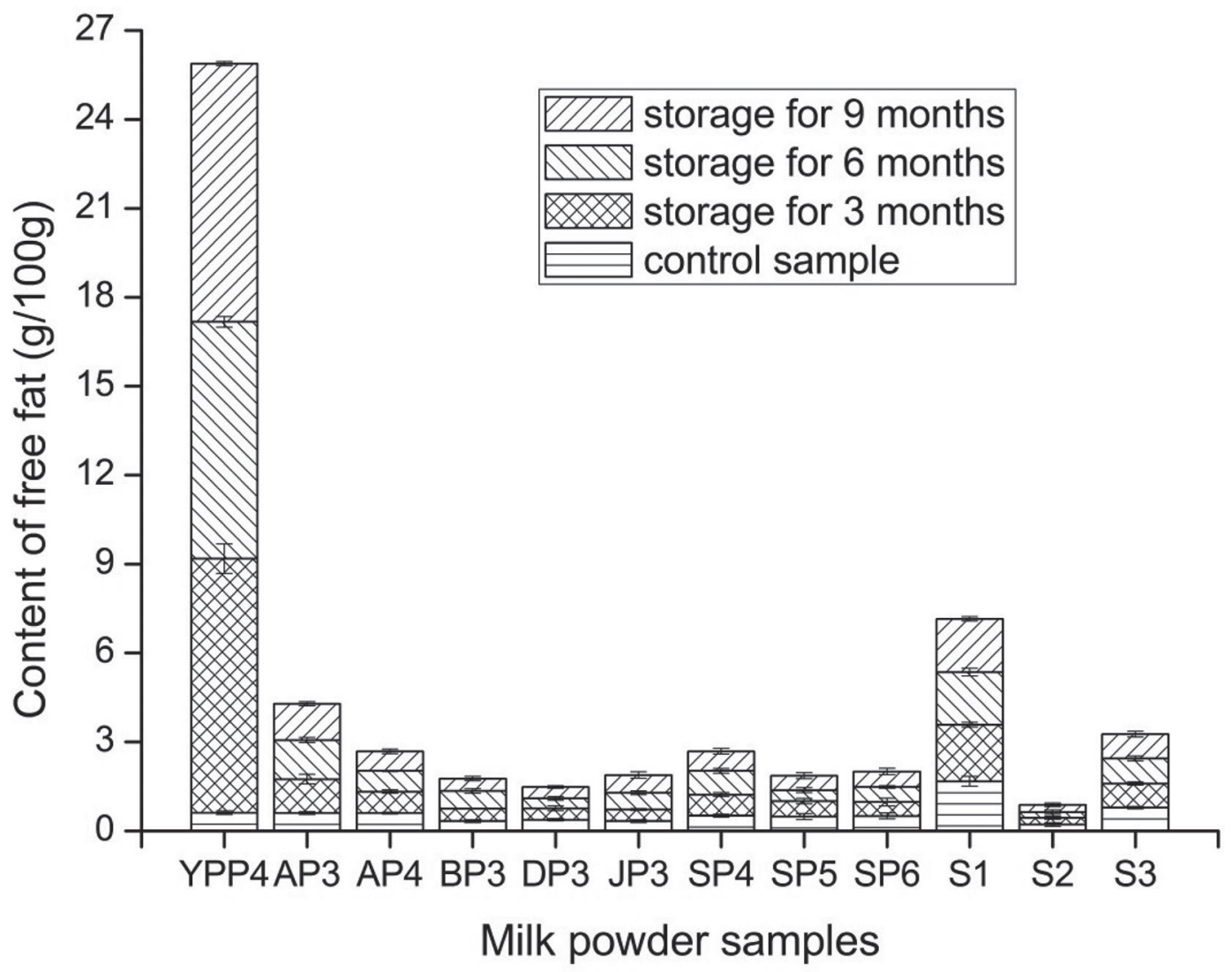

Figure 3. The contents of free fat in the commercial milk powder during storage. Infant formula milk powder = YPP4, AP3, AP4, BP3, DP3, JP3, SP4, SP5, and SP6; whole milk powder $=\mathrm{S} 1, \mathrm{~S} 2$, and S3. Data are expressed as mean values $\pm \mathrm{SD}$. 


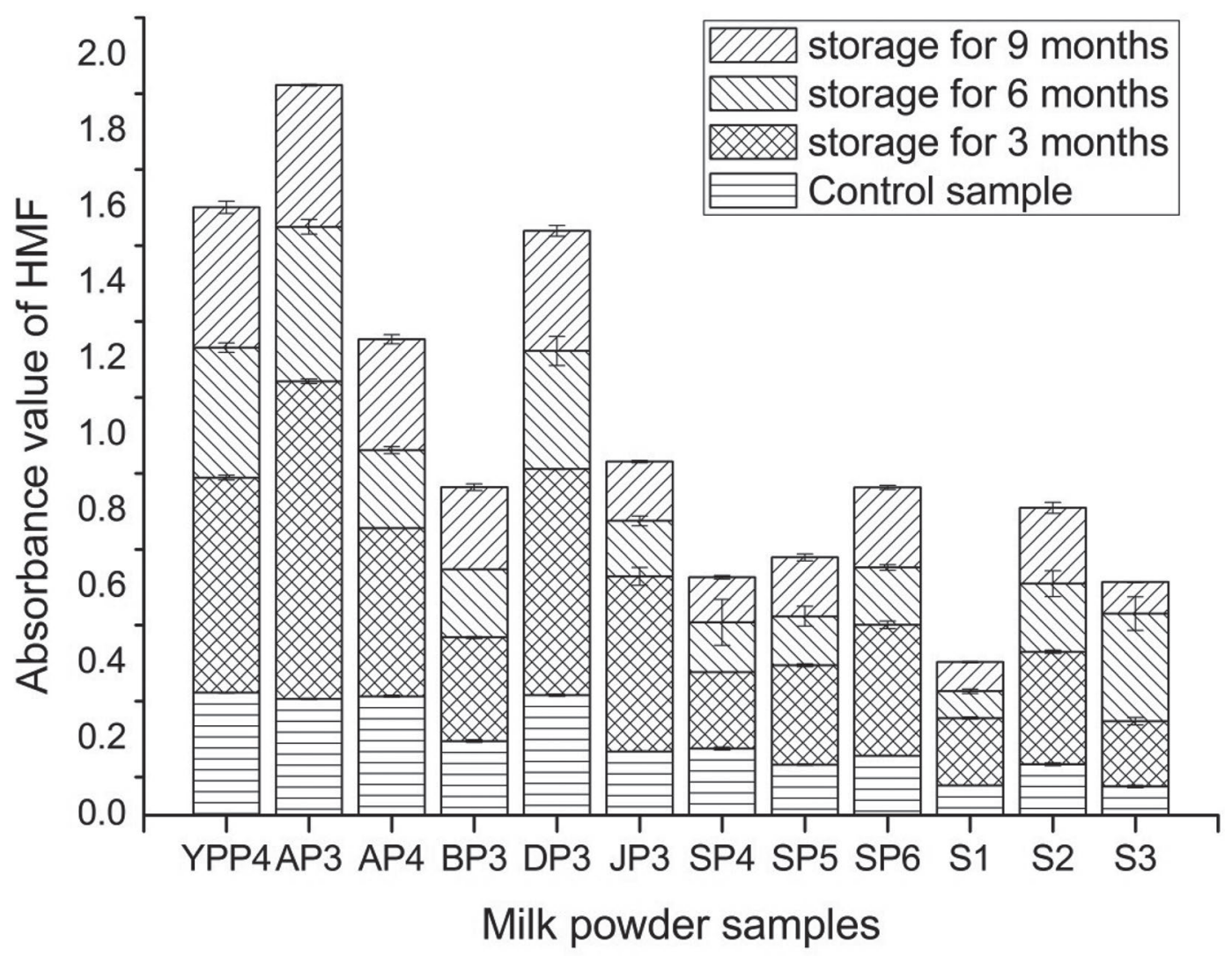

Figure 4. The hydroxymethyl furfural (HMF) values of the commercial milk powder. Infant formula milk powder = YPP4, AP3, AP4, BP3, DP3, JP3, SP4, SP5, and SP6; whole milk powder = S1, S2, and S3. Data are expressed as mean values \pm SD.

to decrease during storage and ranged from 89.30 to 99.88. Changes in color values could be used to assess the extent of Maillard reaction due to the melanoids produced during the reaction (Wu et al., 2010). The results also indicated that the color values noticeably changed during storage of the commercial milk powder for only 3 mo.

\section{Analysis of the Oxidized Flavor Compounds in Commercial Milk Powder}

During storage, milk powder can develop an oxidized flavor that affects its sensory acceptability to consumers. Aldehydes and ketones are the main volatile secondary oxidation products. Many studies have analyzed

Table 2. Yellowness (b) color values of different commercial milk powder during storage (mean \pm SD)

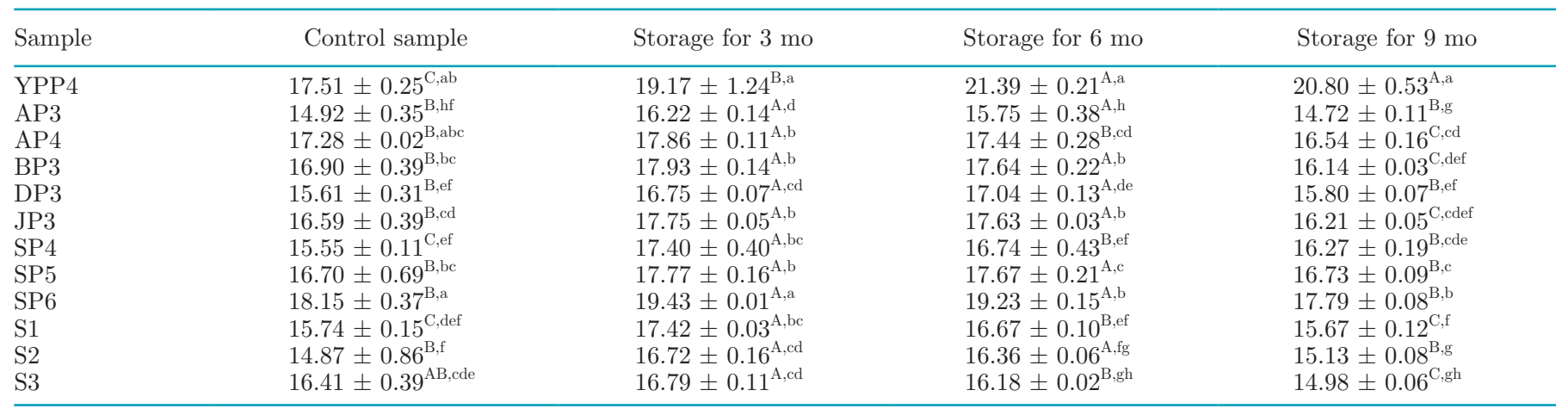

$\overline{\mathrm{A}-\mathrm{C}}$ Different uppercase letters in the same row indicate significant differences between storage times $(P<0.05)$.

${ }^{\mathrm{a}-\mathrm{h}}$ Different lowercase letters in the same column indicate significant differences between the samples $(P<0.05)$. 
Table 3. Brightness (L) color values of different commercial milk powder during storage (mean $\pm \mathrm{SD}$ )

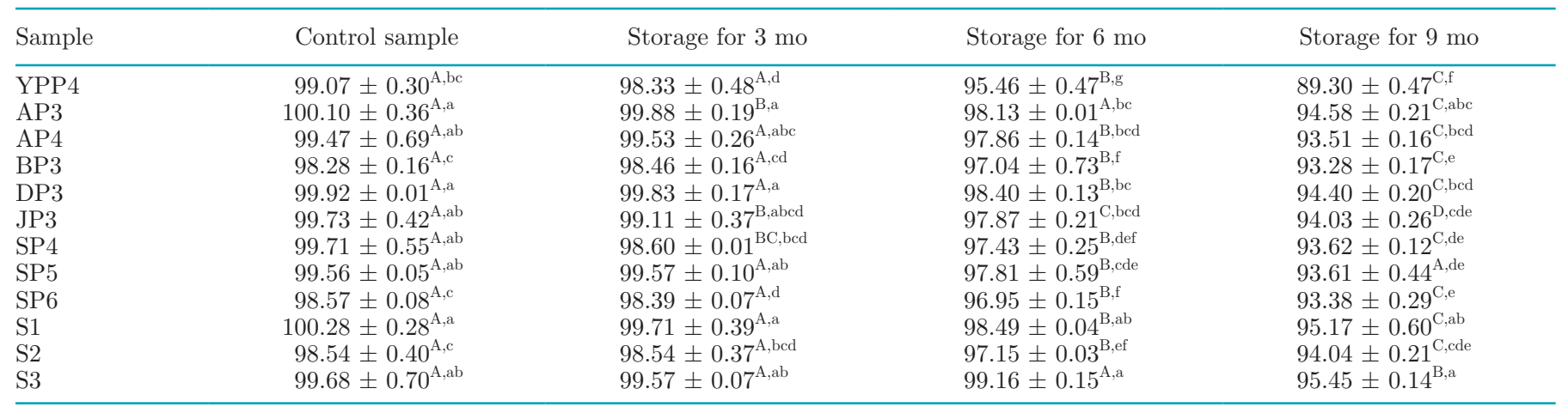

$\overline{\mathrm{A}-\mathrm{D}}$ Different uppercase letters in the same row indicate significant differences between storage times $(P<0.05)$.

${ }^{\mathrm{a}-\mathrm{g}}$ Different lowercase letters in the same column indicate significant differences between the samples $(P<0.05)$.

these volatiles to evaluate the oxidation of milk powder (Lloyd et al., 2009; Li et al., 2013a). The oxidized flavor compounds in different commercial milk powder during storage for 6 and 12 mo are shown in Table 4. In this study, the volatiles hexanal, heptanal, nonanal, 2-heptanone, and 2-nonanone were selected as the typical components responsible for oxidized flavor in milk powder. After 6 mo of storage, the concentrations of the oxidized volatiles were 28.56 to $4,071.28,8.93$ to 301.40 , 8.89 to $560.55,9.08$ to 154.82 , and 1.12 to $184.74 \mu \mathrm{g} / \mathrm{kg}$, respectively. In the SP6, JP3, JP3, and BP3 samples, hexanal was present in high levels ranging from $3,492.03$ to $4,071.28 \mu \mathrm{g} / \mathrm{kg}$, but it was only present at 28.56 and $57.90 \mu \mathrm{g} / \mathrm{kg}$ in the SP4 and S1 samples, respectively. In the BP3, DP3, and JP3 samples, heptanal was present at high levels $(232.32-301.40 \mu \mathrm{g} / \mathrm{kg})$, whereas its contents were lower in SP4 and S1 $(\sim 10 \mu \mathrm{g} / \mathrm{kg})$. In the SP5, JP3, DP3, and BP3 samples, nonanal was present in high levels (434.61-560.55 $\mu \mathrm{g} / \mathrm{kg}$ ), whereas those in the AP3, AP4, S1, SP4, S3, and S2 samples were lower $(8.89-45.58 \mu \mathrm{g} / \mathrm{kg})$. The concentration of 2-heptanone in YPP4 was $154.82 \mu \mathrm{g} / \mathrm{kg}$. The levels of 2-heptanone were lower in the samples of AP3, AP4, JP3, SP4, SP6, and S3 $(9.08-16.67 \mu \mathrm{g} / \mathrm{kg})$. Additionally, there were no significant differences among the above samples $(P$ $>0.05)$. The YPP4 had the highest concentration of 2-nonanone $(184.74 \mu \mathrm{g} / \mathrm{kg})$ and SP4 had the lowest $(1.12 \mu \mathrm{g} / \mathrm{kg})$. These results indicated that the oxidized flavor compounds in commercial milk powder noticeably changed during 6 mo of storage.

After 12 mo of storage, the ranges in the contents of hexanal, heptanal, nonanal, 2-heptanone, and 2-nonanone were 75.91 to $6281.37,16.17$ to $348.52,15.82$ to $974.98,17.91$ to 218.38 , and 1.67 to $182.76 \mu \mathrm{g} / \mathrm{kg}$, respectively. The levels of hexanal in the samples of SP5, JP3, and SP6 reached 5,398.83, 6,055.38, and $6,281.37 \mu \mathrm{g} / \mathrm{kg}$, respectively, whereas the levels were lower in SP4 and S1 $(\sim 80 \mu \mathrm{g} / \mathrm{kg})$. The concentrations of heptanal in BP3, DP3, SP5, SP6, and JP3 ranged from 270.04 to $348.52 \mu \mathrm{g} / \mathrm{kg}$, whereas the concentrations were only 16.17 and $36.22 \mu \mathrm{g} / \mathrm{kg}$ in SP4 and S1, respectively. The concentration of nonanal in JP3 was the highest $(974.98 \mu \mathrm{g} / \mathrm{kg})$, whereas they were only $15.82,16.37,36.14$, and $46.62 \mu \mathrm{g} / \mathrm{kg}$ in AP3, AP4, SP4, and S1, respectively. The YPP4 had the highest level of 2-heptanone $(218.38 \mu \mathrm{g} / \mathrm{kg})$, whereas the levels in the S2, SP4, JP3, and SP6 samples only ranged from 17.91 to $23.75 \mu \mathrm{g} / \mathrm{kg}$. The YPP4 had the highest concentration of 2-nonanone $(182.76 \mu \mathrm{g} / \mathrm{kg})$, whereas the concentrations were 1.67 and $29.28 \mu \mathrm{g} / \mathrm{kg}$ in SP4 and SP6, respectively.

The levels of oxidized flavor compounds in commercial milk powder varied greatly during storage. Hexanal is one of the main oxidized volatiles, and its content increased noticeably in all the samples. The formation of oxidized flavor during the storage of milk powder was the most important factor limiting the flavor quality, shelf life, and applicability (Hough et al., 2002; Whetstine and Drake, 2007; Lloyd et al., 2009). As the concentration of these flavor compounds increased, the flavor intensities from the different oxidized flavor compounds in the milk powder increased, which could seriously influence the acceptability of the milk powder (Lloyd et al., 2009; Li et al., 2013a).

\section{Formation of Free Radicals in Commercial Milk Powder}

A series of free radicals could produce by redox reactions during the storage of milk powder, and the presence of these radicals could be used as an indicator for evaluating the lipid oxidation of dairy products. Figure 5 shows the graphs of the free radicals in different commercial milk powder during storage for 6 mo. The trends in the free radicals in the different samples were not consistent. Among the samples, YPP4, AP3, SP4, 
and S1 had single peaks, which indicated the presence of a single type of free radical. The $\mathrm{g}$ values (g factor) were $2.0044,2.0005,2.0079$, and 2.0070 , respectively. The peak widths of YPP4 and S1 were large (318.87 and $669.78 \mathrm{G}$, respectively), whereas the peak width of SP4 was only $14.78 \mathrm{G}$ (where G means the amplitude).

The value of peak area/mass ratio was highest for S1 and reached $14.26 \times 10^{8}$ (Table 5). The samples of AP4, BP3, DP3, SP5, and S3 had similar free radical graphs, and the peaks occurred in the negative regions. Therefore, these samples had no free radicals. However, the samples of JP3, SP6, and S2 had multimodal peak patterns. Based on the type and intensity of the different free radicals, the values of the peak area/mass ratios were $9.67 \times 10^{7}, 3.36 \times 10^{8}$, and $12.42 \times 10^{6}$, respectively. The JP3, SP6, and S2 samples showed 13, 12 , and 11 peaks, respectively, and the dominant peaks were 6,7 , and 4 , respectively. As $\mathrm{g}=2.1527$, the peak width of JP3 was the largest and reached $21.40 \mathrm{G}$. The peak widths of the free radicals in SP6 were large (g $=2.1484, \mathrm{~g}=2.0908$, and $\mathrm{g}=2.0345$ ), corresponding to $13.75,12.83$, and $11.23 \mathrm{G}$, respectively. The $\mathrm{S} 2 \mathrm{had}$ the largest peak width with $\mathrm{g}=2.0054$, and the peak width was $18.72 \mathrm{G}$. In a previous study, it was found that the $\mathrm{g}$ value of free radicals in milk powder was 2.0054 after 3 mo of storage (Li et al., 2013a), which was similar to the $g$ value of the highest peak of $\mathrm{S} 2$. The existence of free radicals suggested that oxidation might be accelerated during the storage of milk powder (Stapelfeldt et al., 1997; Li et al., 2013a). Nanua et al. (2004) indicated that free radicals existed in whole milk powder when it was prepared with oryzanol rice bran oil. In this study, high contents of free radicals were observed in some of the stored commercial milk powder. No free radicals were present in some of the samples. These results indicated that the trends in the free radicals contents in the stored commercial milk powder were irregular.

\section{Correlation Analysis of the Commercial Milk Powder}

The compositional characteristics of the milk powder can affect the storage stability of the milk powder (Murrieta-Pazos et al., 2012). Table 6 shows the correlation coefficients between the compositional characteristics and the stability indicators of the commercial milk powder. The correlation coefficients between the contents of milk fat and POV, contents of milk fat and free fat, and contents of milk fat and the HMF in the control samples were $0.594,0.639$, and -0.621 , respectively. Both the water activity and the diameter of the fat globules were highly correlated with the stability indicators during the storage of the commercial milk powder. The correlation coefficients between these 2 

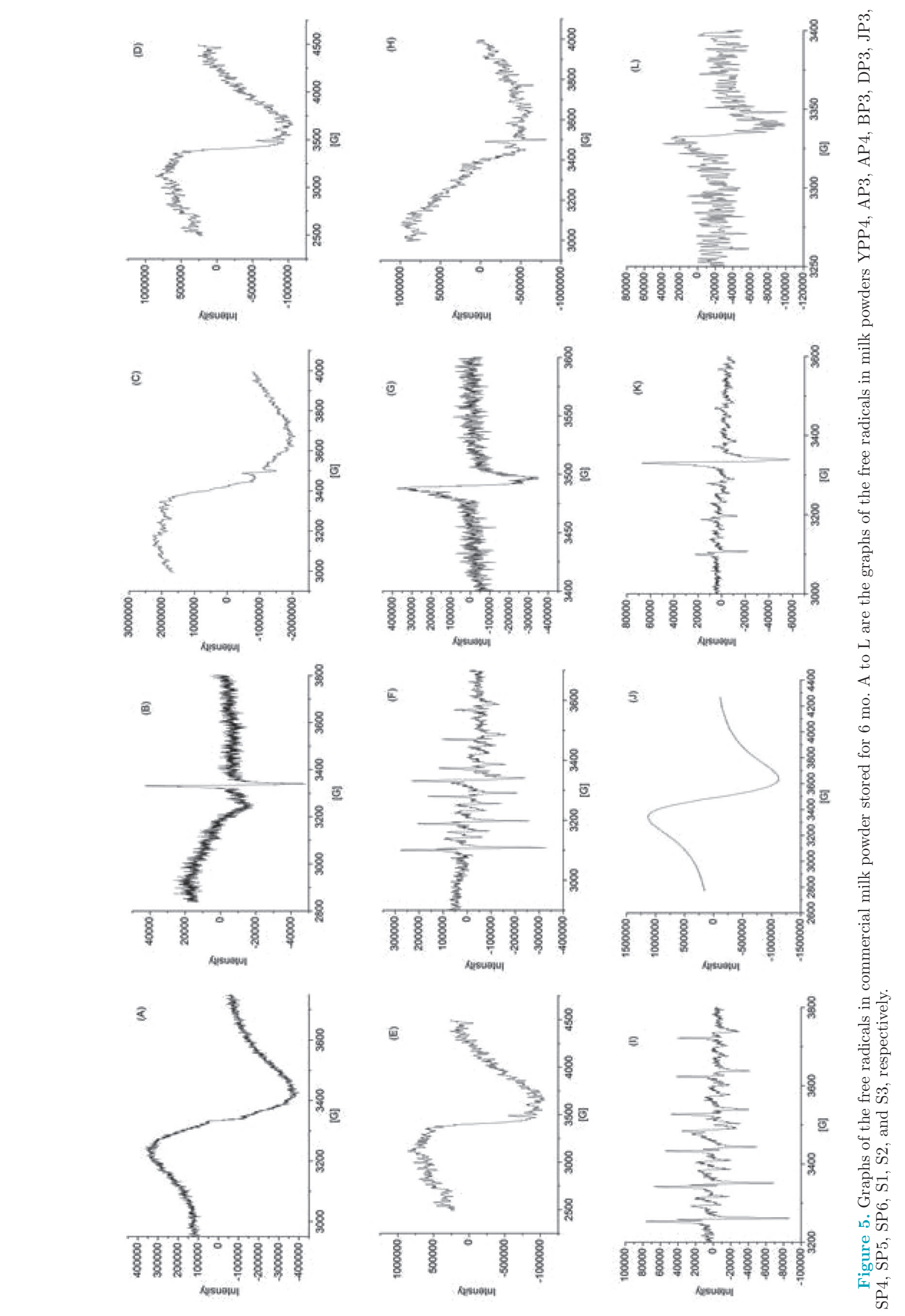

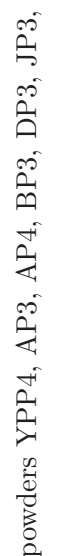


Table 5. Free radicals in different commercial milk powder stored for $6 \mathrm{mo}^{1}$

\begin{tabular}{lccc}
\hline Milk powder sample $^{2}$ & G value & Peak width $(\mathrm{G})$ & $\begin{array}{c}\text { Ratio of peak area } \\
\text { and mass (area/g) }\end{array}$ \\
\hline YPP4 & 2.0044 & $318.8 \pm 5.7$ & $(4.86 \pm 0.49) \times 10^{8}$ \\
AP3 & 2.0005 & $24.1 \pm 0.5$ & $(17.87 \pm 0.05) \times 10^{6}$ \\
SP4 & 2.0079 & $14.8 \pm 0.6$ & $(10.43 \pm 0.15) \times 10^{7}$ \\
S1 & 2.0070 & $669.8 \pm 23.2$ & $(14.26 \pm 0.42) \times 10^{8}$ \\
JP3 & 2.1527 & $21.4 \pm 1.5$ & $(9.67 \pm 1.36) \times 10^{7}$ \\
& 2.0929 & $13.8 \pm 1.6$ & \\
& 2.0384 & $16.6 \pm 4.4$ & \\
& 2.0039 & $13.1 \pm 0.8$ & \\
SP6 & 1.9812 & $11.5 \pm 2.3$ & \\
& 1.9263 & $12.2 \pm 1.5$ & \\
& 2.1484 & $13.8 \pm 2.3$ & \\
& 2.0908 & $12.8 \pm 0.5$ & \\
& 2.0345 & $11.2 \pm 2.1$ & \\
S2 & 2.0080 & $7.8 \pm 0.9$ & \\
& 1.9838 & $9.2 \pm 0.9$ & \\
& 1.9308 & $6.6 \pm 0.2$ & \\
& 1.8796 & $8.5 \pm 0.2$ & \\
& 2.1534 & $11.1 \pm 1.9$ & \\
& 2.0926 & $13.4 \pm 1.2$ & \\
& 2.0366 & $7.6 \pm 0.8$ & \\
& 2.0054 & $18.7 \pm 1.2$ & \\
\hline
\end{tabular}

${ }^{1}$ Data are expressed as mean values $\pm \mathrm{SD}$.

${ }^{2}$ Infant formula milk powder $=$ YPP4, AP3, AP4, BP3, DP3, JP3, SP4, SP5, and SP6; whole milk powder = $\mathrm{S} 1, \mathrm{~S} 2$, and S3.

${ }^{3} \mathrm{G}=$ amplitude.

Table 6. Pearson correlation coefficients between the characteristics and stability indicators of commercial milk powder ${ }^{1}$

\begin{tabular}{|c|c|c|c|c|c|c|c|}
\hline Characteristic & $\begin{array}{l}\text { Storage } \\
\text { time (mo) }\end{array}$ & POV & TBA & $\begin{array}{l}\text { Content of } \\
\text { free fat }\end{array}$ & $\mathrm{HMF}$ & $\begin{array}{l}\text { b color } \\
\text { value }\end{array}$ & $\begin{array}{l}\mathrm{L} \text { color } \\
\text { value }\end{array}$ \\
\hline \multirow[t]{3}{*}{ Milk fat $(\mathrm{g} / 100 \mathrm{~g})$} & Control & $0.594^{*}$ & 0.005 & $0.639^{*}$ & $-0.621^{*}$ & 0.035 & 0.385 \\
\hline & 3 & -0.225 & -0.469 & -0.054 & -0.493 & -0.060 & 0.251 \\
\hline & 9 & 0.083 & -0.165 & -0.060 & $-0.674^{*}$ & -0.199 & 0.395 \\
\hline \multirow[t]{2}{*}{ Protein $(g / 100 \mathrm{~g})$} & Control & 0.551 & -0.131 & $0.737^{* *}$ & -0.514 & -0.017 & 0.318 \\
\hline & 3 & -0.137 & -0.502 & 0.021 & -0.413 & -0.260 & 0.426 \\
\hline \multirow[t]{4}{*}{ Carbohydrate $(\mathrm{g} / 100 \mathrm{~g})$} & Control & -0.570 & 0.094 & $-0.737^{* *}$ & 0.389 & 0.058 & -0.520 \\
\hline & 3 & 0.372 & 0.365 & 0.041 & 0.295 & 0.193 & -0.534 \\
\hline & 6 & 0.242 & 0.181 & 0.051 & 0.103 & 0.227 & $-0.629^{*}$ \\
\hline & 9 & 0.116 & 0.215 & 0.053 & 0.438 & 0.249 & -0.480 \\
\hline \multirow[t]{3}{*}{ Water activity } & Control & -0.424 & -0.083 & 0.098 & $0.630^{*}$ & 0.120 & 0.107 \\
\hline & 3 & -0.475 & 0.108 & $0.861^{* *}$ & 0.529 & 0.310 & -0.221 \\
\hline & 6 & -0.569 & -0.096 & $0.877^{* *}$ & 0.473 & $0.577^{*}$ & $-0.612^{*}$ \\
\hline \multirow[t]{4}{*}{ Diameter of fat globules (nm) } & Control & -0.240 & -0.332 & 0.234 & 0.447 & -0.245 & 0.333 \\
\hline & 3 & $-0.726^{* *}$ & -0.247 & $0.658^{*}$ & 0.262 & -0.033 & -0.095 \\
\hline & 6 & -0.571 & -0.532 & $0.665^{*}$ & 0.374 & 0.212 & -0.303 \\
\hline & 9 & $-0.690^{*}$ & -0.343 & $0.649^{*}$ & 0.314 & 0.358 & -0.444 \\
\hline
\end{tabular}

${ }^{1} \mathrm{POV}=$ peroxide value; $\mathrm{TBA}=$ thiobarbituric acid; HMF $=$ hydroxymethyl furfural; b color $=$ yellowness; $\mathrm{L}$ color $=$ brightness.

*Bilateral correlation is significant at the 0.05 level.

**Bilateral correlation is significant at the 0.01 level. 
Table 7. Pearson correlation coefficients between the characteristics and the typical oxidized flavor compounds in commercial milk powder

\begin{tabular}{|c|c|c|c|c|c|c|}
\hline Characteristic & $\begin{array}{l}\text { Storage } \\
\text { time (mo) }\end{array}$ & Hexanal & Heptanal & Nonanal & 2-Heptanone & 2-Nonanone \\
\hline \multirow[t]{2}{*}{ Milk fat $(\mathrm{g} / 100 \mathrm{~g})$} & 6 & 0.003 & -0.076 & 0.040 & -0.148 & -0.376 \\
\hline & 12 & -0.107 & -0.099 & 0.012 & -0.065 & -0.318 \\
\hline Protein (g/100 g) & 12 & -0.352 & -0.350 & -0.406 & 0.192 & 0.136 \\
\hline \multirow[t]{2}{*}{ Carbohydrate (g/100 g) } & 6 & 0.218 & 0.099 & -0.015 & 0.087 & 0.206 \\
\hline & 12 & 0.240 & 0.102 & 0.050 & -0.193 & 0.006 \\
\hline \multirow[t]{2}{*}{ Particle size (mm) } & 6 & -0.316 & -0.186 & -0.365 & 0.005 & 0.465 \\
\hline & 12 & -0.244 & -0.255 & -0.366 & 0.400 & 0.471 \\
\hline \multirow[t]{2}{*}{ Diameter of fat globules (nm) } & 6 & $-0.676^{*}$ & -0.453 & -0.462 & 0.534 & 0.532 \\
\hline & 12 & $-0.699^{*}$ & $-0.717^{* *}$ & $-0.592^{*}$ & 0.571 & 0.438 \\
\hline
\end{tabular}

*Bilateral correlation is significant at 0.05 level.

**Bilateral correlation is significant at 0.01 level.

compositional characteristics and the contents of free fat were 0.861 to 0.877 and 0.649 to 0.665 , respectively. The correlation coefficients between the water activity and the POV, HMF, b color value, and $\mathrm{L}$ color value ranged from -0.326 to $-0.569,0.473$ to $0.601,0.310$ to 0.662 , and -0.221 to -0.761 , respectively. The correlation coefficients between the diameter of the fat globules and the POV and the TBA ranged from -0.571 to -0.726 and -0.247 to -0.532 , respectively.

Table 7 shows the correlation coefficients between the characteristics and the typical oxidized flavor compounds in the commercial milk powder. These results showed that the water activity and the diameter of the fat globules played a substantial role in the oxidized flavor compounds. The water activity mainly affected the concentrations of 2-heptanone and 2-nonanone in the commercial milk powder and the correlation coefficients reached 0.721 to 0.770 and 0.654 to 0.823 , respectively. A negative correlation was observed between the diameter of the fat globules and the contents of aldehydes. The correlation coefficients ranged from -0.453 to -0.717 . In addition, the diameter of the fat globules was positively correlated with the 2 -heptanone and 2-nonanone contents, and the correlation coefficients ranged from 0.534 to 0.571 and from 0.438 to 0.532 , respectively. Changes in the POV, TBA, and the contents of free fat could indicate the occurrence of lipid oxidation during the storage of the milk powder (Guillen-Sans and Guzman-Chozas, 1995; Cluskey et al., 2006; Romeu-Nadal et al., 2007; Vignolles et al., 2007; Zafar et al., 2017). Changes in the HMF level and the $b$ and $L$ values could indicate the degree of Maillard reaction (Wu et al., 2010; Chavez-Servin et al., 2015). Aldehydes, ketones, and other compounds responsible for the oxidized flavor could be formed by the Maillard reaction (Nursten, 1997). The correlation analysis of the commercial milk powder indicated that the water activity and the diameter of the fat globules had high correlations with the oxidation stability during storage.

\section{CONCLUSIONS}

The composition and particle characteristics of the commercial milk powder were different. The POV of the commercial milk powder could change during 3 mo of storage. The trends in the values of TBA and free fat were not consistent during storage. The HMF values of most of the samples increased at the beginning of storage and then decreased. Similarly, the color values changed noticeably during storage of the samples for 3 mo. The concentrations of the oxidized flavor compounds in the commercial milk powder varied greatly, and the content of hexanal increased the most. The types and contents of free radicals in the commercial milk powder were inconsistent. The water activities and diameters of the fat globules in the commercial milk powder had high correlations with the oxidation stability during storage.

\section{ACKNOWLEDGMENTS}

The authors acknowledge the financial support from the Natural Science Foundation of Zhejiang Province (Project Number LY17C200005), the Zhejiang Provincial Collaborative Innovation Center of Food Safety and Nutrition (Project Number 2017SICR107), and the National Natural Science Foundation of the People's Republic of China (Project Number 31401557).

\section{REFERENCES}

Birchal, V. S., M. L. Passos, G. R. S. Wildhagen, and A. S. Mujumdar. 2005. Effect of spray-dryer operating variables on the whole milk powder quality. Dry. Technol. 23:611-636. 
Cesa, S., M. A. Casadei, F. Cerreto, and P. Paolicelli. 2012. Influence of fat extraction methods on the peroxide value in infant formulas. Food Res. Int. 48:584-591.

Chavez-Servin, J. L., K. de la Torre Carbot, T. Garcia-Gasca, A. I. Castellote, and M. C. Lopez-Sabater. 2015. Content and evolution of potential furfural compounds in commercial milk-based infant formula powder after opening the packet. Food Chem. 166:486491.

Chavez-Servin, J. L., A. I. Castellote, and M. C. Lopez-Sabater. 2006. Evolution of potential and free furfural compounds in milk-based infant formula during storage. Food Res. Int. 39:536-543.

Cluskey, S. M., J. F. Connolly, R. Devery, B. O'Brien, and J. Kelly. 2006. Lipid and cholesterol oxidation in whole milk powder during processing and storage. J. Food Sci. 62:331-337.

Guillen-Sans, R., and M. Guzman-Chozas. 1995. Aldehydes in food and its relation with the TBA test for rancidity. Eur. J. Lipid Sci. Technol. 7:285-286.

Guinee, T. P., M. A. E. Auty, and M. A. Fenelon. 2000. The effect of fat content on the rheology, microstructure and heat-induced functional characteristics of cheddar cheese. Int. Dairy J. 10:277-288.

Hough, G., R. H. Sanchez, G. Garbarini de Pablo, R. G. Sanchez, V. S. Calderon, A. M. Gimenez, and A. Gambaro. 2002. Consumer acceptability versus trained sensory panel scores of powdered milk shelf-life defects. J. Dairy Sci. 85:2075-2080.

Keeney, M., and R. Bassette. 1959. Detection of intermediate compounds in the early stages of browning reaction in milk products. J. Dairy Sci. 42:945-960.

Li, Q., L. W. Zhang, Y. C. Zhang, H. X. Yi, M. Du, X. Han, C. F. Guo, J. Y. Li, and C. H. Xue. 2012. Determination of lactose, glucose and galactose contents in fermented milk by HPLC. J. Chinese Food Sci. 4:162-166.

Li, Y. H., L. W. Zhang, and W. J. Wang. 2013b. Heat-induced changes in volatiles of milk and effects of thermal processing on microbial metabolism of yogurt. J. Food Biochem. 37:409-417.

Li, Y. H., L. W. Zhang, W. J. Wang, and X. Han. 2013a. Differences in particle characteristics and oxidized flavor as affected by heatrelated processes of milk powder. J. Dairy Sci. 96:4784-4793.

Lloyd, M. A., M. A. Drake, and P. D. Gerard. 2009. Flavor variability and flavor stability of U.S.-produced whole milk powder. J. Food Sci. 74:S334-S343.

Lynch, J. M., D. M. Barbano, and J. R. Fleming. 2002. Determination of the total nitrogen content of hard, semihard, and processed cheese by the Kjeldahl method collaborative study. J. AOAC Int. 85:445-455.

Marie-Laure, V., L. Christelle, C. L. Floch-Fouere, E. Jean-Jacques, M. Serge, J. Romain, and S. Pierre. 2010. Fat supramolecular structure in fat-filled dairy powders: A tool to adjust spray-drying temperatures. Dairy Sci. Technol. 90:287-300.

Marie-Laure, V., J. Romain, L. Christelle, and S. Pierre. 2007. Free fat, surface fat and dairy powders: Interactions between process and product. A review. Lait 87:187-236.
Murrieta-Pazos, I., C. Gaiani, L. Galet, R. Calvet, B. Cuq, and J. Scher. 2012. Food powders: Surface and form characterization revisited. J. Food Eng. 112:1-21.

Nanua, J. N., J. U. McGregor, and S. C. Grace. 2004. Effects of high oryzanol rice bran oil on free radical formation and oxidation of whole milk powder. Int. J. Agric. Rural Dev. 5:134-139.

Nursten, H. E. 1997. The flavour of milk and dairy products: I. Milk of different kinds, milk powder, butter and cream. Int. J. Dairy Technol. 50:48-56.

Romeu-Nadal, M., J. L. Chavez-Servin, A. I. Castellote, M. Rivero, and M. C. Lopez-Sabater. 2007. Oxidation stability of the lipid fraction in milk powder formulas. Food Chem. 100:756-763.

Stapelfeldt, H., B. R. Nielsen, and L. H. Skibsted. 1997. Effect of heat treatment, water activity and storage temperature on the oxidative stability of whole milk powder. Int. Dairy J. 7:331-339.

Sun, T. T. 2013. Influence of common technological treatment on richfat-milk oxidation stability. MS Thesis. School of Food Science and Engineering, Harbin Institute of Technology, Harbin, China.

Thomsen, M. K., L. Lauridsen, L. H. Skibsted, and J. Risbo. 2005a. Temperature effect on lactose crystallization, Maillard reactions, and lipid oxidation in whole milk powder. J. Agric. Food Chem. 53:7082-7090.

Thomsen, M. K., L. Lauridsen, L. H. Skibsted, and J. Risbo. 2005 b. Two types of radicals in whole milk powder. Effect of lactose crystallization, lipid oxidation, and browning reactions. J. Agric. Food Chem. 53:1805-1811.

Turner, J. A., R. S. T. Linforth, and A. J. Taylor. 2002. Real-time monitoring of thermal flavor generation in skim milk powder using atmospheric pressure chemical ionization mass spectrometry. J. Agric. Food Chem. 50:5400-5405.

Vignolles, M.-L., R. Jeantet, C. Lopez, and P. Schuck. 2007. Free fat, surface fat and dairy powders: Interactions between process and product. A review. Lait 87:187-236.

Whetstine, M. E. C., and M. A. Drake. 2007. The flavor and flavor stability of skim and whole milk powders. K. R. Cadwallader, M. A. Drake, and R. McGorrin, ed. Pages 217-251 in Flavor of Dairy Products. ACS Publishing, Washington, DC.

Wu, H. L., Z. Q. Wang, C. Han, Z. N. Peng, and Y. Q. Chen. 2010. Factors affecting the Maillard reaction. Xiandai Shipin Keji 26:441-444.

Ye, A., H. Singh, D. J. Oldfield, and S. Anema. 2004. Kinetics of heatinduced association of $\beta$-lactoglobulin and $\alpha$-lactalbumin with milk fat globule membrane in whole milk. Int. Dairy J. 14:389-398.

Zafar, U., V. Vivacqua, G. Calvert, M. Ghadiri, and J. A. S. Cleaver 2017. A review of bulk powder caking. Powder Technol. 313:389401

Zou, L. L. 2009. Processing technology of cheese produced by goat and cow milk. MS Thesis. School of Food Science, Shaanxi Normal University, Xian, China. 